\title{
DUAL-USE TECHNOLOGIES OF CONCERN IN CONTEXT OF BIOSAFETY (REVIEW)
}

\author{
Ashcheulova T., Ambrosova T. \\ Kharkiv National Medical University, Kharkiv, Ukraine \\ https://doi.org/10.35339/ic.8.1.4-9
}

\begin{abstract}
One of the main prerequisites for creation and dissemination of bioethics in the world was the concept of dual use in medical and biological sciences, which is defined as the direction of unintentional creation of biological threats in research or implementation of new biotechnologies. To determine the range of dual-use research that could potentially generate products, technologies, or knowledge whose misuse could harm large numbers of people or the environment and that are biosafety-relevant, the international term Dual Use Research of Concern (DURC) is used. Actualization of the debate on the dilemma of dual use in biomedical sciences is due to, on the one hand, the international community's attempt to minimize the potential for destructive use of biomedical research, on the other hand, the active search for effective ways to raise awareness of their social and moral responsibility for implementation of the results of scientific developments in the field of life. This article considers the definition of terms that define the field of DURC in the context of biosafety, which in recent decades have undergone a number of semantic changes. The article also outlines the modern general concept of DURC, defines the categories by which DURC is defined, and outlines the scope of policy on the implementation of control over DURC. Informing the scientific community engaged in biomedical research about the problem issues of DURC biotechnology is a key component of biosafety. Modern biotechnology and related biosafety issues should be applied to society needs, but without compromising human and environmental safety. Systematic consideration of all these disputable questions of the dual-use dilemma with the involvement of all stakeholders will allow to form a rational biosafety policy for biotechnology.
\end{abstract}

Keywords: biosafety, investigation of DUAL-USE TECHNOLOGIES OF CONCERN, DURC criteria, DURC recommendations.

At the global level, biosafety issues related to the protection of humans, animals, plants and the environment from biological threats are becoming increasingly important, especially in the context of modern information technology and access to global biosafety information [1].

One of the main prerequisites for the creation and dissemination of bioethics in the world was the concept of dual use in medical and biological sciences, which is defined as the direction of unintentional creation of biological threats in

Corresponding Author:

Tetiana Ambrosova, MD, PhD, Professor of the Department of Propaedeutics of Internal Medicine № 1, Basis of Bioethics and Biosafety, Kharkiv National Medical University, Kharkiv, Ukraine. E-mail: ambrosovatm@gmail.com research or implementation of new biotechnologies. The knowledge cannot be safe or dangerous, it acquires either a benefit or a threat to society only in the process of implementing specific practical goals [2].

The biosafety strategy in biomedical sciences is mainly characterized by an approach that assumes that research results working with biological agents and designed to expand scientific knowledge can also be used for the purposes other than the original, predictable and legal. To refer to a range of dual-use studies that could potentially generate products, technologies, or knowledge whose misuse could harm large numbers of people or the environment and that are biosafetyrelevant, the international term Dual Use Research of Concern (DURC) is used.

This article considers the definition of the terms that defines the scope of DURC in the 
context of biosafety, which in recent decades has undergone a number of semantic changes. The article also outlines the modern general concept of DURC, defines the categories used to define DURC, outlines the scope of policy on the implementation of control over DURC.

The actualization of the debate on the dilemma of dual use in biomedical sciences is due to, on the one hand, the international community's attempt to minimize the potential for destructive use of biomedical research, on the other hand, the active search for effective ways to raise awareness of their social and moral responsibility for the results of scientific development implementation in the field of life [3].

The use of the latest knowledge for destructive purposes is not a new problem of the modern science. This topic has undergone significant transformations in the recent decades in the context of the rapid development of scientific thought. Active discourse around modern biotechnology attracts the attention of scientists, politicians, regulators. A key aspect of DURC debate is whether biotechnology research should be active or whether this will not lead to the spread of diseases dangerous to humanity, whether these studies can become a threat to humanity. In other words, the concern of mankind is related to the question: Can the sciences about life become sciences about death? Researchers believe that such development is quite possible and therefore actively discuss the limitation of research and public information on the results of these studies in the field of biomedical research and the creation of potentially dangerous biotechnology [4].

The concept of dual use was in the past widely used to refer to the knowledge and technology for civil and military use. Today, in the context of the accumulation of dangerous knowledge in the life sciences, there is concern about how the new knowledge and methods may affect the development of biological weapons. The issue that biological agents (objects of medical and biological research) have the potential to be used as weapons of mass destruction is discussed [5]. In some cases, they also have the potential to spread worldwide through infection, thereby endangering the lives or health of large numbers of people, or harming the environment or other important interests, even in the case of local release [6]. Thus, DURC issue is a matter of potential biological weapons and bioterrorism that needs public scrutiny and attention.

The ethical problems of DURC danger are not a completely new moral and ethical challenge of the latest technologies. For example, physicists working on nuclear energy (Manhattan Project) discussed the ethical dangers of the possible use of nuclear research for military purposes, which proved justified after the first use of nuclear weapons against Japan. Another example of the possibility of dual use was the active debate after the start of the project on the creation of recombinant DNA. Biomedical scientists have been concerned about the implications of their research. The Asilomar Conference of 1975 was dedicated to recombinant DNA and was initiated because the scientists were concerned that DNA research, if left uncontrolled, could have unpredictable and devastating consequences for both human health and the global ecosystem. At the conference, geneticists discussed the possibility that common harmless microorganisms could become pathogenic to humans through the introduction of the genes that make them resistant to antibiotics, or allow microorganisms to produce dangerous toxins or transform them into carcinogens. The quote of the Nobel laureate, physicist Max Bourne: "Science destroys the ethical foundation of civilization" (1968), which can be interpreted as the fact that the latest technology always causes moral and ethical dilemmas, is world-known.

Biomedical sciences differ from nuclear research in that they are conducted worldwide in commercial and academic laboratories, rather than in the laboratories owned by national governments whose activities can be more strictly regulated and controlled at the governmental level. In the context of biomedical sciences, and, in particular, in the field of biotechnology, there are no clear boundaries and distinctions between defensive and offensive biological programs, and it is often difficult for scientists to justify a scientific biological experiment, although under the Convention on the Prohibition of Biological and Toxic Weapons, development of biological weapons is illegal, as is their production, acquisition, transfer, storage, accumulation and use.

DURC discussion has become active at the beginning of the new century. In 2000, Harvard University molecular biologist Matthew Messelson voiced the potential threats to the concept of dual use. In his opinion, over the next century, as our ability to change fundamental life processes continues to move rapidly, we will not only be able to invent additional ways to destroy life but also to obtain the possibility to manipulate it including the processes of cognition, development, reproduction and inheritance. Therefore, the movement to such a world will distort the accelerating revolution in biotechnology, so as to 
damage its huge potential for mutually beneficial application, and can have hostile consequences for the course civilization [7].

DURC concept originally referred to the technologies that had both civilian and military purposes. Following the terrorist attacks of September 11, 2001 and subsequent bioterrorist attempts to spread the anthrax to the United States, the term became broader, which was proposed in 2004 in a report by the Committee to Study Standards and Practices to Prevent the Destructive Application of Biotechnology to the US National Research Council (hereinafter referred to as Fink Committee) entitled "Biotechnological Research in the Age of Terrorism". The main premise of this report is the quote "Most of all biotechnology that serves human health can be used for hostile purposes. The main components of bioterrorism are likely to be based on the materials and techniques that are easy to obtain because they are accessible. The most important element of protection against bioterrorism is accelerated development of technologies to establish our ability to detect and treat diseases. The abuse between the spread of technologies that protect us and the spread of technologies that threaten us is a major component of the dualuse dilemma [8].

The dual-use dilemma, according to the report of Fink Committee, is that any advances in biomedical sciences can be easily used by dangerous subjects to develop biological weapons. Experts of Fink Committee formulated three potential definitions of the dual use of science and technology: 1. has both civilian and military applications; 2 . can be used both for useful/good and for harmful/ dangerous purposes; 3 . has both useful/good and harmful/dangerous purposes related to weapons, in particular weapons of mass destruction [8].

Fink Committee based its recommendations on the analysis of the state of regulation of science and technology at the time. The Committee found that "current national and international directives and regulations for basic and applied research in the field of genetic engineering can guarantee the physical safety of laboratory workers and the environment by preventing contact with the pathogens or "new" organisms or the effects of such agents. However, they do not currently provide for measures to prevent the possible use of tools, technology, or research knowledge for aggressive military or terrorist activities. In addition, no national or international oversight body currently has the legal authority or self-responsibility to evaluate a proposed research activity to determine whether the benefits of the proposed research outweigh the risks associated with it and the likelihood of its abuse" [8].

Fink Committee identified 7 specific categories of research to be monitored. These include the following research areas:

1. a technique that demonstrates how to make a vaccine ineffective;

2. providing resistance to therapeutically useful antibiotics or antiviral agents;

3. enhancing the virulence of pathogens or providing virulence to non-pathogenic agents;

4. increase of pathogen transmissibility;

5. change in the range of hosts of pathogens;

6. techniques that make it possible to evade diagnostic methods;

7. conversion of biological substances or toxins into weapons.

Fink Committee also developed recommendations for the prevention/mitigation of possible misuse of biomedical research results [8]:

Recommendation 1: Education of the scientific community: We recommend that national and international professional associations and related organizations and institutions establish programs to train natural scientists on the dualuse dilemma of biotechnology and their responsibilities to reduce risks.

Recommendation 2. Review of Experimental Plans: We recommend that the Department of Health and Human Services (DHHS) strengthen the existing control system for recombinant DNA experiments conducted by the National Institutes of Health to establish a control system for seven classes of experiments (experiments of interest) using microbial pathogens that cause concern about their potential for proper use.

Recommendation 3. Verification at the stage of publications: We recommend, based on the selfgovernment of scientific and scientific journals, to check publications for potential risks to national security.

Recommendation 4: Establishment of National Scientific Advisory Board on Biological Weapons: We recommend that the Department of Health and Social Services establish National Scientific Advisory Board on Biological Weapons (NSABB) to provide advice, guidance and leadership in the oversight and control system.

Recommendation 5. Additional elements of protection against misuse: We recommend that the federal government rely on current legislation and regulations on for periodic inspections of NSABB to ensure the protection of biological materials and the monitoring of personnel working with these materials. 
Recommendation 6 . The role of biomedical sciences in efforts to prevent bioterrorism and biological warfare: We recommend that the national security and law enforcement communities develop new channels of sustainable communication with the biomedical industry in order to reduce the risks of bioterrorism.

Recommendation 7. Coordination of International Supervision: We recommend that international political and scientific circles establish an International Biosafety Forum to develop and promote agreed national, regional and international activities in addition to the system we recommend for the United States".

One of the important recommendations of Fink Committee ("Biotechnological Research in the Age of Terrorism") was the formation of a standing committee to discuss the problems of potential threats associated with biotechnology in synthetic biology. In addition to creating such a new body, it was recommended that the mainstream scientific community improve education, namely, begin to study the ethics of dual use by changing existing publication requirements, and establishing the channels for communication between research laboratories and security and law enforcement agencies.

The debate, initiated by the report of Fink Committee, continued in 2006 when a report entitled "Globalization, Biosecurity, and the Future of Biomedical Sciences" was published under the auspices of the US National Academy. This program document was developed by the Committee on Technology Development and Prevention for the Requirements of Bioterrorism and Biological Weapons (Lemon-Relman Committee) [9]. This report not only addressed the issues highlighted in Fink's report, but also outlined a much wider range of scientific areas that may address the issue of dual use.

The main difference between the reports of Fink and Lemon-Relman was the scale of the study of biomedical technologies. Thus, Fink Committee focused mainly on the problems of threats in synthetic biology, while Lemon-Relman Committee did not limit itself to a specific area, but presented a more general concept of understanding biomedical threats and mechanisms for preventive response to them, and focused on that biomedical research is dangerous and requires development of control systems for all biomedical sciences.

Lemon-Relman Committee (2006) formulated a general concept for biotechnology. In particular, the experts concluded that biotechnology is a global and potential threat in their nature, and the potential threat of any biotechnology is much broader than just that posed by traditional pathogens and toxins. The report stated that the biological substance used in the mail attacks was anthrax, the 'classic' choice of those intending to wage biological warfare. Moreover, it is becoming increasingly important that biomedical scientist take all possible measures to ensure that their work is not used for criminal purposes. Correspondingly, this requires biomedical workers to pay much more attention to the danger than that currently exists and to be more willing to take on that responsibility. Finally, the experts of LemonRelman Committee conclude that a new standard is needed, and it must appear on a global scale [9].

Lemon-Relman Committee fully endorsed and reaffirmed the policy of promoting free and open exchange of information in the field of biomedical sciences and made several recommendations [9]:

1. to apply a broader view of the threat spectrum.

2. to strengthen and expand scientific and technical experience within and between securityrelated communities.

3. to accept and promote the general culture of awareness and the general sense of responsibility in the world community of scientists of medical and biological branch.

4. to strengthen .. the health care system ... and existing response and recovery capabilities.

One of Fink committee guidelines in 2004 was the recommendation to the Department of Health and Human Services to establish National Scientific Advisory Board on Biological Weapons (NSABB) to provide advice, guidance, and leadership in the oversight and control system. In accordance with these recommendations, the US Government established the National Scientific Advisory Board on Biosecurity (NSABB) in 2005 . The NSABB is currently a federal advisory committee that reviews biosecurity and dual-use research commissioned by the US government. NSABB has up to 25 voting members with a wide range of experience in biomedical sciences such as molecular biology, microbiology, infectious diseases, biosafety, health, veterinary, plant health, national security, biosecurity, law enforcement, scientific publications and other related scientific and applied fields.

Regarding the responsibility of researchers for publishing the results of the study, DURC evaluations are currently conducted by the journal editors who may seek advice from the NSABB 
staff. However, the NSABB is a federal advisory committee, and only the US government can delegate tasks to the board, which in turn can only advise the US government. Therefore, outside organizations, such as journals, cannot refer issues directly to the Board. Thus, the journal editors are the only arbiters for the publication of manuscripts describing DURC [10].

At present, various NSABB offices and programs work on a wide range of issues, including biosafety, biosecurity, genetic testing, genomic data sharing, subject protection, organization and management of the National Institutes of Health $(\mathrm{NIH})$, and the results and value of research funded by the NIH [11]. This is achieved through a wide range of analyzes and reports, comments on the new policy proposals, and the development of policy proposals for consideration by the NIH, the federal government, and the public.

In 2007, the NSABB prepared a document entitled "Proposed Control System for Dual Use Life Sciences Investigation: Strategies for Minimizing the Potential Misuse of Research Information" [12]. This document identifies that some research has the potential to be "dual-use" and that it is the research that generates information and products that can be used for both beneficial and harmful purposes. The NSABB has introduced an international definition of DURC in the field of biomedical sciences, "Research that, based on current understanding, can be reasonably anticipated to provide knowledge, products, or technologies that could be directly misapplied by others to pose a threat to public health and safety, agricultural crops and other plants, animals, the environment, or material" [12].

In addition, the NSABB provided a roadmap and tools for identifying scientific work that could fall into the DURC category, and proposed mechanisms for disseminating such information, including writing of accompanying editorials.

The NSABB has proposed criteria for determining DURC, namely, it describes seven categories of experiments that can be used to identify the work that could potentially be DURC, with the wording according to which the studies ncluded in any of these categories "should be particularly carefully assessed for compliance with the criterion of dual-use studies of concern". The seven criteria are clear and easily applied to manuscripts to identify potential DURC.

The seven criteria of possible DURCs defined by the NSABB are [12]:

(1) Enhances the harmful effects of a biological agent or toxin (2) Violates immunity or the effectiveness of immunization without clinical and / or agricultural justification (3) Belongs to a biological agent or toxicity to clinically and / or agriculturally useful prophylactic or therapeutic interventions against that agent or toxin or facilitates its ability to avoid detection methodologies. (4) Increases the stability, transmission, or ability to spread a biological agent or toxin. (5) Changes the host range or tropism of a biological agent or toxin. (6) Increases susceptibility of the host population. (7) Forms a new pathogenic agent or toxin or restores a destroyed or extinct biological agent.

Informing the research biomedical community about the problematic issues of DURC biotechnology is a key component of biosafety. Modern biotechnology and related biosafety issues should be applied to social needs, but without compromising human and environmental safety. Systematic consideration of all these disputable aspects of the dual-use dilemma with the involvement of all stakeholders will allow to form a rational biosafety policy for biotechnology.

A key point here is the need to determine that the risks of dual use can and should be seen in the context of a range of surveillance measures, including monitoring the responsibility of scientists to minimize the risks of misuse of their research.

Thus, in order to solve the problems of DURC, there are approaches that, on the one hand, are aimed at developing a culture of biosafety based on social and moral responsibility of scientists in the field of high risk DURC, and on the other hand, to avoid their unnecessary restrictions or censorship in the direction of freedom of scientific thought.

\section{Conflict of interests}

The authors of the article declare no conflict of interests.

\section{References}

1. Miller, S., Selgelid, M.J. (2007). Ethical and philosophical consideration of the dual-use dilemma in the biological sciences. Sci.Eng.Ethics 13:523-580. doi: 10.1007/s11948-007-9043-4.

2. Douglas, T., Savulescu, J. (2010). Synthetic biology and the ethics of knowledge. Journal of Medical Ethics, 36, 687-693.

3. Ehni, H.J.,(2008). Dual-use and the ethical responsibility of scientists. Archivum Immunologiae Therapiae Experimentalis, 56, 147-152. 
4. Atlas, R.M., Dando, M. R. (2006). The dual-use dilemma for the life sciences: perspectives, conundrums, and global solutions. Biosecurity and Bioterrorism, 4, 276-286.

5. Millet, P. (2010). The Biological Weapons Convention: Securing biology in the twenty-first century. Journal of Conflict and Security Law, 15 (1), 25-43.

6. Meselson M., Robinson J.P. (2002) A draft convention to prohibit biological and chemical weapons under international criminal law. In Yepes-Enriquez R, Tabassi L (eds) Treaty Enforcement and International Cooperation in Criminal Matters, pp. 457-469. Cambridge, UK: Cambridge University Press.

7. Meselson, M. (2000) Averting the Hostile Exploitation of Biotechnology CBW Conventions Bulletin, $48,16-19$.

8. National Research Council (2004). Biotechnology Research in an Age of Terrorism. Washington, DC: The National Academies Press.

https://doi.org/10.17226

9. National Research Council (2006). Globalization, Biosecurity, and the Future of the Life Sciences. Washington, DC: The National Academies Press.

https://doi.org/10.17226/11567

10. Berns, K.I., Casadevall, A., Cohen, M,L. (2012). Public health and biosecurity: adaptations of avian flu virus are a cause for concern. Science, 335, 660-661. doi:10.1126/science.1217994.

11. National Institutes of Health. (2012). United States Government policy for oversight of life sciences dual use research of concern.

http://osp.od.nih.gov/office-biotechnology-activities/biosecurity/dual-use-research-concern.

12. National Science Advisory Board for Biosecurity.(2007). Proposed framework for the oversight of dual use life science research: strategies for minimizing the potential misuse of research information. National Science Advisory Board for Biosecurity, National Institutes of Health, Bethesda, MD.

http://osp.od.nih.gov/sites/default/files/resources/Framework\%20for\%20transmittal\%20duplex\%20910-07.pdf

Received: 19-Nov-2020

Accepted: 08-Feb-2021 